\title{
ANALISA PANJANG ANTRIAN DENGAN TUNDAAN PERSIMPANGAN BERSINYAL (STUDI KASUS PERSIMPANGAN PATAL-PUSRI)
}

\author{
Hapri Dharmayanto ${ }^{1)}$, Ismail ${ }^{2)}$ \\ Program Studi Teknik Sipil Fakultas Teknik Universitas Palembang \\ Jalan Dharmapala No.1A Bukit Besar Palembang 30139 \\ e-mail : hapridy@gmail.com ${ }^{1)}$, ismailthr64@gmail.com ${ }^{2}$
}

\begin{abstract}
the intersection of is one of the part of the thoroughfare that unite some streets around the stadium and connecting some streets around the stadium to the point where it is a region happened quite a lot though the whole range of the movement of vehicles who end up creating long queues and exceptionally large, This situation is commonly known term traffic congestion.Research that we do is analysis long his line with tundaan at a crossroads bersinyal with four phase, The roads are the type $42 \mathrm{~d}$ and 4 / / was 2 .The method of calculation used manual kapaitas ( mkji indonesia s road , 1997 ). The implementation of the was conducted over 2 ( two the day the day the day monday and tuesday, on the day! april 2018.A method of analysis the intersection of conducted from geometry simpang, volume traffic, environmental conditions, and class obstacles side.The results of the study obtained wide pendekat the north and south 7.50 meters, and the east and west 9.50 meters. Volume traffic at the junction as pendekat north the way of r.Abdul rojak of 2450 kend per hour, pendekat the east the way akbp check agus of 3401 kend per hour, the south the way of r.Soekamto of 2469 kend per hour and jalan mp mangku a country as large 5174 kend per hour.Long his line the north of $2576 \mathrm{smp} /$ hours, the east of $2368 \mathrm{smp} /$ hours, the south of 4708 smp / hours and the west of 4891 kend per hour. To know the intersection of service levels seen from large .As for the value of exceptionally large in a northern direction 21,43 sec / smp , 19.75 $\mathrm{sec} / \mathrm{smp}$, east , south $17,94 \mathrm{sec} / \mathrm{smp}$ and the west $20,87 \mathrm{sec} / \mathrm{smp}$.Category b it means good service levels .
\end{abstract}

Keywords : Long His Line, Delay, Service Level, MKJI, 1997

\section{LATAR BELAKANG}

Simpang di Kota Palembang sebagian besar merupakan simpang sebidang, sehingga akan menyebabkan terjadinya konflik yang menimbulkan beberapa permasalahan lalu lintas seperti kemacetan. Untuk mengurangi atau meminimalkan konflik tersebut, simpang yang ada di atur dengan menggunakan Alat Pemberi Isyarat Lalu Lintas (APILL).Maksud dari penelitian ini adalah untuk menganalis variabel kinerja persimpangan dengan lampu lalu lintas.Variabel kinerja simpang tersebut adalah waktu hilang, kapasitas simpang dan derajat kejenuhan, panjang antrian, kendaraan terhenti dan tundaan. Tujuan yang hendak dicapai melalui penelitian ini secara khusus adalah menampilkan kinerja simpang yang dikaitkan dengan volume lalu lintas Penelitian ini akan menganalisis variabel kinerja simpang dengan menggunakan MKJI yang dilakukan dalam kondisi awal dan terbangun untuk waktu puncak dan kondisi awal pada waktu puncak siang dan sore. Pada pendekatan MKJI, variabelnya adalah ukuran kota, geometrik, arah arus, volume, kecepatan dan fase. Setelah dilakukan analisis akan diperoleh variabel kinerja simpang dengan lampu lalu lintas yang meliputi derajat kejenuhan, panjang antrian, 
jumlah waktu henti dan tundaan. Rekomendasi yang disampaikan untuk untuk meningkatkan kinerja Simpang Patal - Pusri dengan melaksanakan pengaturan lalu lintas arah utara - timur dan selatan - barat.Ruas jalan adalah ruas jalan AKBP cek agus dengan ruas jalan MP Mangku Negara dan ruas jalan Soekamto dengan ruas jalan Residen Abdul rojak. Dimana ruas - ruas jalan menjadikan pertemuan disimpang PatalPusri yang kita sebut simpang Underpass kota Palembang.

\section{TINJAUAN PUSTAKA}

\subsection{Simpang Bersinyal}

Simpang merupakan bagian dari ruas-ruas jalan yang bertemu dengan simpang,apakah simpang bersinyal atau tak bersinyal. Biasanya di simpang ini sering terjadi konflik untuk mengendalikan konflik biasanya dipasang Apill.Simpang dapat didefinisikan sebagai daerah umum dimana dua jalan atau lebih bergabung atau bersimpangan, termasuk jalan dan fasilitas tepi jalan untuk pergerakan lalu lintas di dalamnya.

\subsection{Arus lalu lintas}

Menurut MKJI (1997), arus lalu lintas (Q) untuk setiap gerakan (belok kiri QLT, lurus QST, dan belok kanan QRT) dikonversikan dari kendaraan per jam menjadi satuan mobil penumpang (smp) perjam dengan menggunakan ekivalen kendaraan penumpang (emp) untuk masing-masing pendekat terlindung dan terlawan.

\subsection{Faktor penyesuaian lebar pendekat ( $\mathrm{Fw}$ ) \\ Penyesuaian lebar pendekatan} diperoleh dari gambar dan dimasukkan dalam formulir USIG-II. Variabel masukkan adalah lebar rata - rata pendekatan persimpangan $\mathrm{W}_{1}$ dan tipe persimpangan IT, batas - batas waktu yang diberikan dalam gambar adalah batas nilai untuk dasar empiris dari manual.

\subsection{Lebar pendekat efektif}

Lebar pendekat efektif (We), ditentukan berdasarkan data dari lebar pendekat (Wa), lebar masuk (Wmasuk) dan lebar keluar (Wkeluar). Untuk semua pendekat, apabila pergerakan belok kiri langsung (left turn on red) diperkenankan dan tidak terpengaruh oleh pergerakan lain dalam pendekat (pergerakan belok kiri langsung dapat melewati antrian kendaraan dengan arah atau membelok kanan pada saat lampu merah)

\subsection{Data masukan}

Pada tahap ini akan diuraikan secara rinci tentang kondisi - kondisi yang diperlukan untuk mendapatkan data masukan dalam menganalisis simpang tak bersinyal.

\subsection{Derajat Kejenuhan (Degree of Saturation, DS)}

Derajat kejenuhan adalah hasil arus lalu lintas terhadap kapasitas biasanya dihitung perjam

\subsection{Tundaan (D)}

Tundaan adalah rata - rata waktu tunggu tiap kendaraan yang masuk dalam pendekat.

\subsection{Peluang Antrian (QP\%)}

Peluang antrian dinyatakan pada range nilai yang didapat dari kurva hubungan antara peluang antrian (QP\%) dengan derajat jenuh (DS), yang merupakan peluang antrian dengan lebih dari dua kendaraan di daerah pendekat yang mana saja, pada simpang tak bersinyal.

\subsection{Penilaian Perilaku Lalu Lintas}

Manual ini terutama direncanakan untuk memperkirakan kapasitas dan perilaku lalu-lintas pada kondisi tertentu 
berkaitan dengan rencana geometrik jalan, lalu-lintas dan lingkungan.

\subsection{Geometrik Persimpangan}

Geometrik persimpangan merupakan dimensi yang nyata dari suatu persimpangan

\subsection{Kondisi Arus Lalu Lintas}

Arus lalu lintas (Q) pada setiap gerakan (belok kiri $\mathrm{Q}_{\mathrm{LT}}$, lurus $\mathrm{Q}_{\mathrm{ST}}$, dan belok kanan $\mathrm{Q}_{\mathrm{RT}}$ ) dikonversi dari kendaraan per jam menjadi satuan mobil penumpang (smp) per jam dengan menggunakan ekivalen kendaraan penumpang (emp) untuk masing-masing pendekat terlindung dan terlawan.

\subsection{Jenis kendaraan}

Jenis kendaraan yang melintasi persimpangan berdasarkan PU Bina Marga jenis golongan yang masing masing golongan terdiri atas beberapa jenis kendaraan

\section{METHODOLOGI}

Pada metode penelitian terdapat beberapa langkah yang harus dilakukan untuk mendapatkan hasil dari penelitian yang meliputi studi pendahuluan untuk mengetahui persimpangan, kemudian dilanjutkan dengan menentukan lokasi survey. Langkah selanjutnya adalah identifikasi permasalahan,lalu dilanjutkan dengan pengumpulan data sekunder dan data primer Penelitian. 


\section{HASIL DAN PEMBAHASAN}

\subsection{Kapasitas Simpang (C)}

Kapasitas simpang adalah tempat kumpulnya arus yang melewati pada suatu titik persimpangan yang terdiri dari ruas jalan.

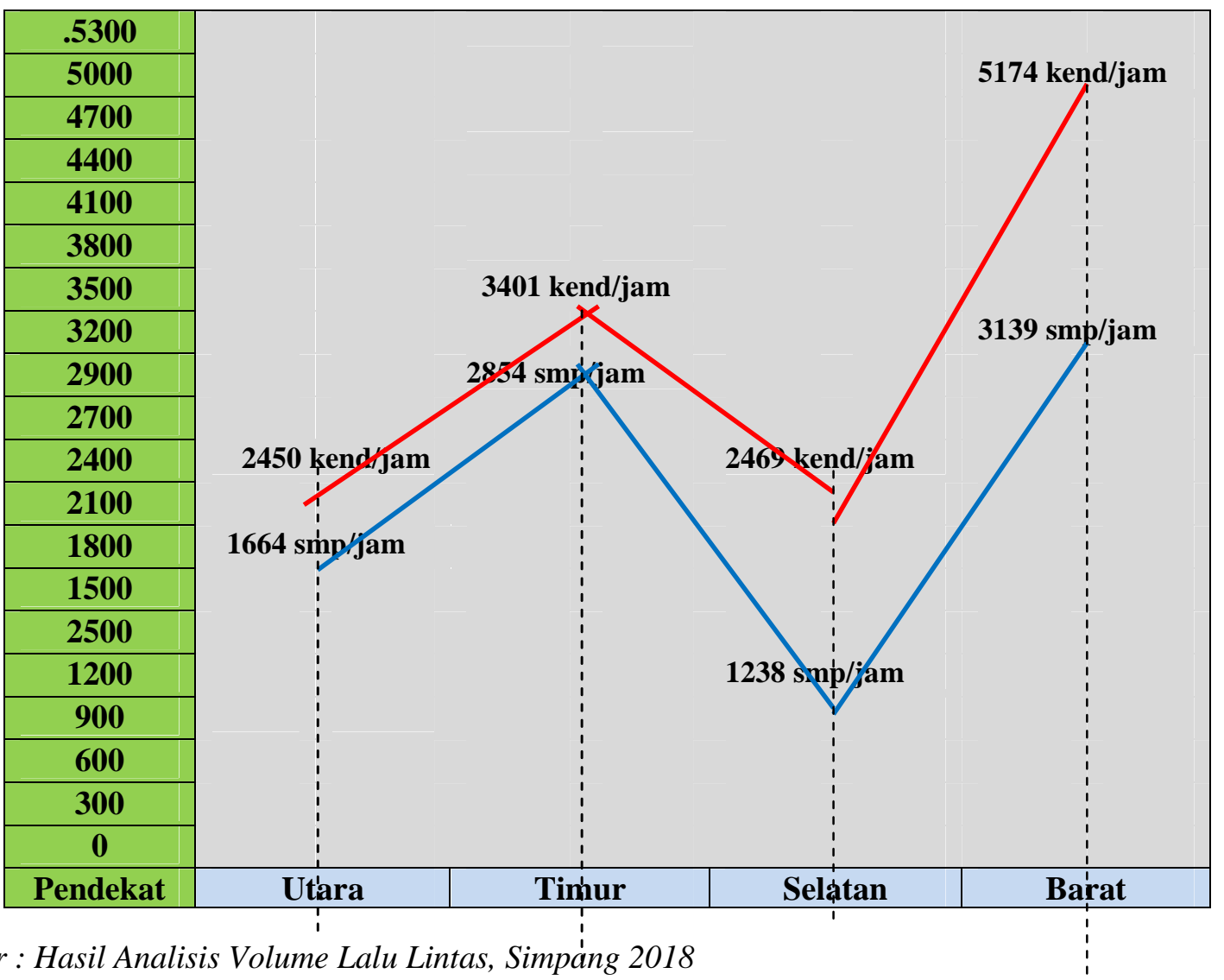

Sumber : Hasil Analisis Volume Lalu Lintas, Simpàng 2018

Besarnya volume lalu lintas yang melewati simpang pendekat Patal-pusri dari ruas jalan pendekat utara jalan R.A.Rojaksebesar 2450 $\mathrm{kend} / \mathrm{jam}$, dari ruas jalan pendekat timur sebesar $3401 \mathrm{kend} / \mathrm{jam}$, dari ruas jalan pendekat Selatanjalan R.Soekamto sebesar $2469 \mathrm{kend} / \mathrm{jam}$ dan pendekat Barat dari jalan MP Mangku Negara sebesar 5174 kend/jambesar kapasitas ditentukan oleh ruasjalan. 


\subsection{Panjang Antrian}

Panjang antrian terjadi saat waktu lampu merah pada simpang bersinyal. Pendekatan sebagai jalan masuk pada persimpangan

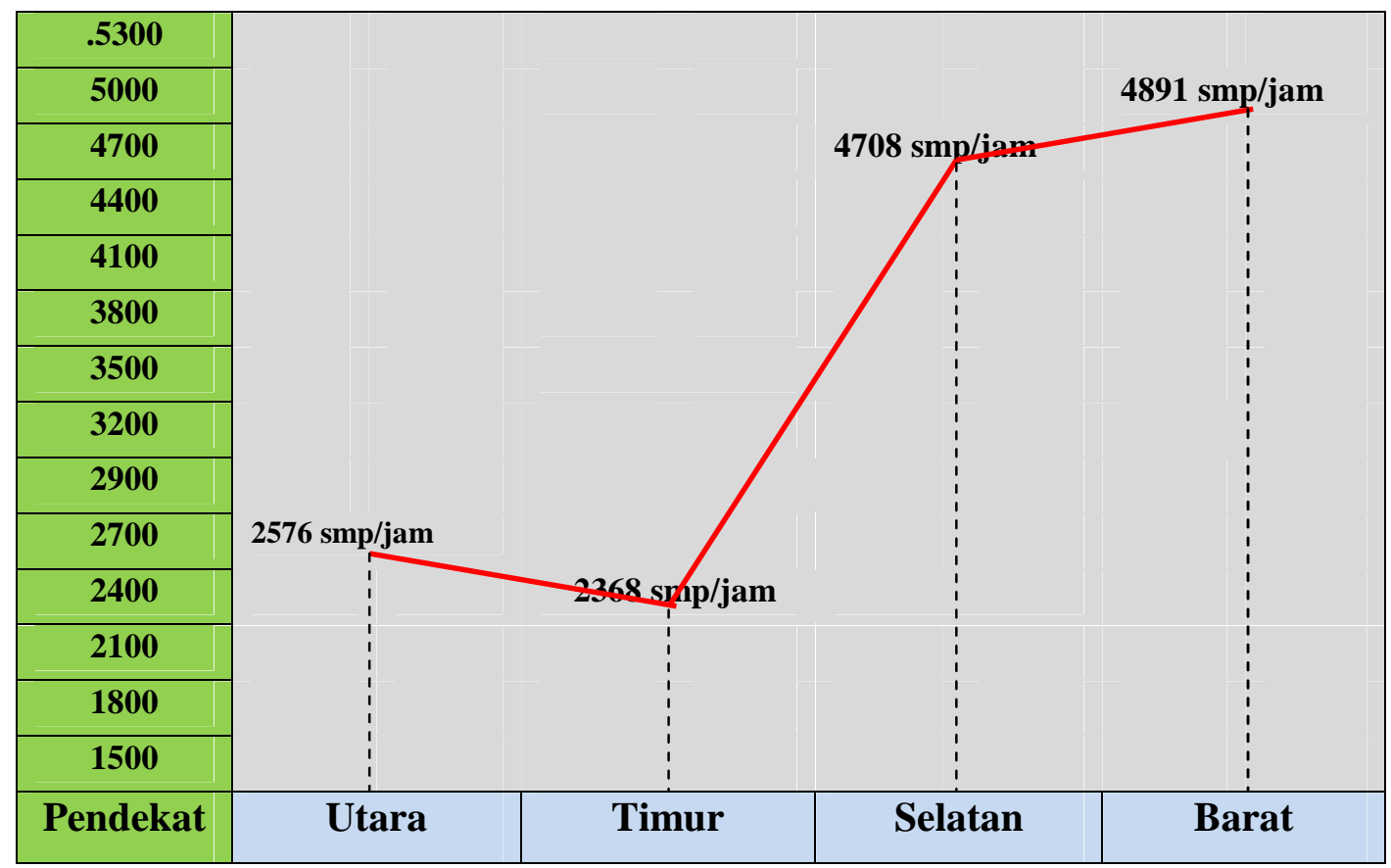

Sumber : Hasil Analisis Panjang Antrian 2018

Panjang antrian pendekatan barat jalan MP Mangku Negara terbesar yaitu $4891 \mathrm{smp} / \mathrm{jam}$ ini akibat besarnya volume lalu lintas dari kapasitas yang tersedia menyebabkan derajat kejenuhan
(DS) terjadi besar, sehingga menjadikan antrian kendaraan yang melewati MP Mangku Negara. Ini terjadi pada saat lampu merah aktip

\subsection{Tundaan}

Tundaan lalu lintas adalah waktu tunggu yang disebabkan oleh interaksi lalu lintas dengan gerakan lalu lintas yang bertentangan. Tundaan terjadi juga akibat kendaraan yang membelok dipersimpangan dan/atau yang terhenti oleh lampu merah

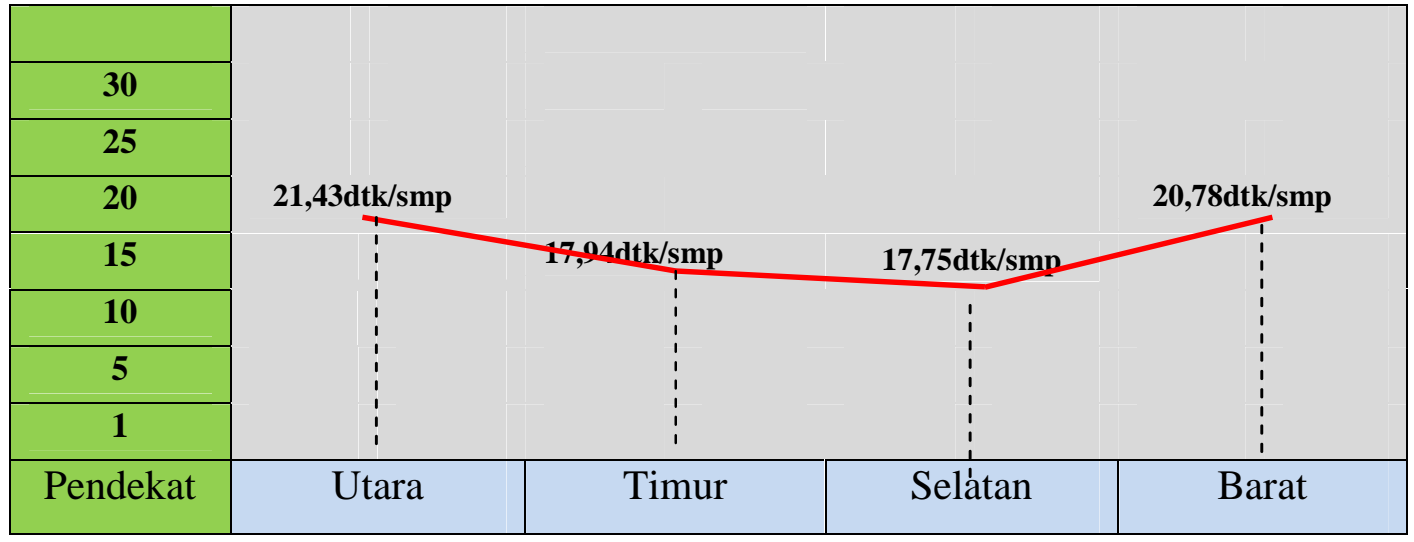

Gambar 1 Tundaan Kendaraan 
Dari gambar 1 terlihat tundaan rata - rata simpang Patal-Pusri untuk kondisi eksisting yang tertinggi terjadi pada pendekat Utara dari jalan residen A Rojak yang tertinggi. Tundaan

\section{KESIMPULAN}

Berdasarkan hasil analisis dari data yang telah dilakukan, maka dapat disimpulkan sebagai berikut :

1. Volume maksimum yang melawati persimpangan Patal - Pusri, dari arah jalan AKBP Cek Agus sebesar 3401 kend/jam, dari arah R.Soekamto sebesar $2469 \mathrm{kend} / \mathrm{jam}$, dari arah jalanMP mangku Negara sebesar 5174 kend/jam dan terakhir dari arah jalan A.rojak sebesar $2450 \mathrm{kend} / \mathrm{jam}$.

2. Panjang antrian arah utara sebesar 2576 smp/jam, arah timur sebesar 2368 smp/jam, arah selatan sebesar 4708 smp/jam dan arah barat sebesar 4891 kend/jam. Untuk mengetahui persimpangan tingkat pelayanan dilihat dari tundaan, adapun nilai tundaan arah utara 21,43 detik/smp, timur 19,75 detik/smp, selatan 17,94 detik/smp dan arah barat 20,87 detik/smp.

3. Dari tundaan, adapun nilai tundaan arah utara 21,43 detik/smp, timur 19,75 detik/smp, selatan 17,94 detik/smp dan arah barat 20,87 detik/smp. Tingkat pelayanan katagori B artinya baik. yang sering terjadi hasil pengamatan dilapangan yaitu barat sebesar 20,78 dtk/smp, pada jalan AKBP Cek Agus (Golf-kuto)

\section{DAFTAR PUSTAKA}

1. Anonim1997, Manual Kapasitas Jqlan Indonesia (MKJI), Direktorat Jenderal Binamarga, Direktorat Bina Jalan Kota.

2. Clarkson H.Oglesby dan R Gary Hicks, 1990,Teknik Jalan Raya, Nova, Jakarta.

3. Hobbs,F,D,1995,Perencanaan Dan Teknik Lalulintas Perkotaan, Edisi kesatu,Gadjah Mada University Press, Yogyakarta.

4. Munawar,Ahmad,2004,ManajemenLaluli ntas Perkotaan,penerbit bela offset ,Yogyakarta.

5. Malkhamah S,1994, survey,Lampu lalulintas, manajemen lalulintas,KMTSFakultas Teknik Universitas Gadjah Mada, Yogyakarta.

6. Morlok Edwar K,1988, Pengantar Teknik Dan Perencanaan Transportasi,Erlangga, Jakarta.

7. Sukirman, Silvia, 1994, Dasar-Dasar Perencanaan Geometrik Jalan, Penerbit, Nova, Bandung.

8. Alter R.J, Hounsell,N.B,1990, Highway traffic analysis and design,London 